\title{
Impact of Stress on the Employees of Habib Bank Limited in Pakistan
}

\begin{abstract}
Akbar Ali ${ }^{1}$, Saeed Khalid ${ }^{2}$, Waseem Khalid ${ }^{3}$, Rao Junaid ${ }^{4}$
${ }^{1}$ Dean, Management Information Systems, NUST, Karachi Campus

${ }^{2}$ Dean, Industrial \& Manufacturing Engineering, NUST Karachi Campus

${ }^{4}$ Management Information Systems, NUST Karachi Campus

${ }^{5}$ Management Information Systems, NUST Karachi Campus

A B S T R A C T

The main aim of this study was to evaluate the real impact of the stress on employee performance level at Habib Bank Limited. As Stress was considered as emerging sensitive issue in this competitive and growth oriented era, increasing expectations of employees lead to physiological and psychological stress problems that declined their performance level. In this study, Survey Questionnaire had been applied for this data collection. Data collected from 150 respondents of various branches of Habib Bank Limited was analyzed through correlation test. The analysis concluded that employees experienced stress when the demands/expectations of the organization go beyond employee's capability. Stress was the outcome of this role stressor: "role conflict", "role ambiguity" as well as the "role overload". Stress occurred when employees had no clarity about their task and duties and were overburdened with work. This research work might help the banking sector to know about effects and reasons of stress on employee's performance level. Using these findings, banking sector can develop strategies to avoid stress for improving employee performance.
\end{abstract}

Keywords: stress, role stressors, role conflict, role ambiguity, role overloaded, performance.

\section{INTRODUCTION}

The introduction of this study comprises of problem background, the problem stated, research context, Aim of study, research hypothesis, and limitation of the study and Ethical consideration which are further elaborated in under mentioned parts: 


\section{Problem Background}

Nowadays, Organizations are becoming competitive and to maintain growth and competitive position. Organization's expectations about work performance from employees are rising. Employees escalating responsibilities require them to perform more efficiently and effectively for longer hours to meet rising expectations of the organization. To meet organization's expectations, employees face never ending and challenging problem in an organization that is called stress.

Stress is one of the sensitive issues that create an imbalance in individual's life that leads to depression, as a result individual's health, attitude and work behavior are affected. The concept of stress was first introduced in the life of science. The state in which individual makes efforts to retain its original state, when pressure, force or tension exposed on them is called stress (Selye 1936).A state when an individual opposed his desired opportunity, resources or demand. Stress is when individuals are unable to fulfill demands of the organization, the adverse physical and psychological reactions occur in them (Moorhead and Griffen, 1998).

The nature of stress is not always bad, it may have negative or positive effects. When the individuals are capable of coping up the requirements/ demands of the organization, the effect of stress is positive but when that demand level goes beyond the individual's capability, the effects are negative on employees. Mostly, the demands of organizations exceed the bearable limit of individuals, that's why usually it is perceived that stress has a negative impact on individuals.

Here it is evident that stressor may be of any nature but is to be addressed seriously. Ambiguous role/function is a cause of stress that keeps the employee in doubts and troubles. Similarly, overburdening the people beyond their capacity results in very deep stress. Role conflict also causes the employee to fight amongst each other and remain confused, leading to a feeling of a high degree of stress. This all concludes that 'stress' as the state is directly proportional to the degree of stressors.

Stress is the result of stressors (Kahn 1964). For this research, Role stressor theory is followed in order to find out the impact of stress on the employee job performance. The higher a number of stressors results in high level of stress. Stressors include "Role 
ambiguity", "Role overload" and "Role conflict".

\section{Problem Statement}

Any organization is composed of human, financial and physical resources. To achieve maximum profit and minimum conflicts and costs, proper set up of these resources is required. Human resource is responsible for proper structure and allocation of resources. When any individual is responsible for managing other resources of organization especially human resource in a way that the organization receives maximum profit with minimum costs and conflicts, the chances of dissatisfaction are there and this dissatisfaction leads to stress. Further, it is said that there is no one without some percentage of stress that could be external or internal to the organization. Stress levels affect job satisfaction of the employees and relevant work performance. This new arena is known as "age of anxiety and stress" (Coleman, 1976), as the better (maximum) outcome is demanded by most organizations. Job or work stress is taken as observed a dysfunctional element for the members and organization "(Kahn, Wolfe, Quinn, Snoek, \& Rosenthal, 1964)". Stress in the workplace is considered as adverse consequences. Hence this study will examine the level of stress on workers efficiency and effectiveness level to analyze the effects of stress.

\section{Research Context}

This research will explain the impact of stress on employee performance level at Habib Bank Limited. Stress is a result of role stressors. Stressor theory "(Kahn et al, 1964)". There are three types of role stressors that are explained in this theory i.e. "role conflict", "role ambiguity" and "role overload". For this research, the impact of these role stressors was examined on employee's job performance level and the focus group was managerial and supervisory level employees of Habib Bank Limited.

\section{Aim of Study}

The very purpose of this study was to understand how stress (Role stressors) impact on employee performance. Stress has both negative and positive effects but usually, employees faced negative effects due to high expectations of organization and role stressors. The effort was being put to dig in both cases in depth to bring the reality on the surface. 


\section{Hypotheses:}

Hypothesis 1

Ho1: There was no "impact of role conflict on employee" performance

Ha1: There was a significant "impact of role conflict on employee" performance Hypothesis 2

Ho2: There was no impact of role ambiguity on employee performance

$\mathrm{Ha} 2$ : There was a significant impact of role ambiguity on employee performance

Hypothesis 3

Ho3: There was no impact of role overload on employee performance

Ha3: There was a significant impact of role overload on employee performance

\section{Limitation of Study}

The research work of this study has some limitations. Considering the time and cost as a very high-level constraint, the sample size was taken from HBL bank and data was collected from 150 managerial and supervisory level employees.

\section{Ethical consideration}

While carrying out research, the ethical consideration was taken into account to avoid the issue of plagiarism. Accordingly, Turnitin test of the whole article has been done. The data collected from the primary sources has been kept confidential and will not be disclosed.

\section{LITERATURE REVIEW}

\subsection{Stress}

Hans Selye first identified the concept of stress in the biological context in the 1930s. Later he expanded his concept and included "unsuitable physiological response to any demand". Stress is the force or pressure exposed on individuals, who struggles against these forces and maintain its true state is stress (Selye, 1936). When a great amount of pressure is placed on individuals and they show undesirable response because they are worried that they are unable to deal with that pressure is called stress.

According to Arnold and Fledman (2000), stress is the reaction showed by individuals when new aggressive factors are introduced into the workplace. This 
definition also suggests that the response to stressful states is personalized and can lead to behavioral, emotional, physiological and perceptual change.

Robbins (2004) investigated that a dynamic condition when someone is confronted with demand, opportunity or constraint is called stress. Here it is evident that stress is not always a negative but it may also be positive while we proceed towards some potential gain. Moorhead and Griffen (1998) found out that stress may be an adaptive response to a stimulus that puts an individual under psychological or physical pressure. Same way, "Sherman, Bohlander, and Snell (1996)", said that stress may be the result of mental, physical or emotional factors.

"Taylor Shelley (1995)" translated the concept of stress and termed stress as the negative experience of emotions along with biochemical, cognitive, behavioral and physiological changes that alter events and its effects. Bennett (1994) said that stress is a sum of psychological and physical symptoms experienced by an individual while adapting to an environment.

Stress is a condition or experience faced by the individual when he/she is unable to meet the rising expectations of organizations. Stress is considered negative/bad but it's not always bad. As, when stress rises up to the manageable level, the results are effective and performance level increases (positive results) but once that stress level exceeds the manageable limit, the performance of individual declines. Several types of research have been done on stress and various models were developed to know reasons and its effects of stress upon the performance.

Based on the high level researches of eminent scholars like Hans Selye (1930), Selye (1936), Arnold \& Fledman (2000), Robbins(2004), Moorhead \& Griffen (1998), Sherman, Bohlander \& Snell (1996), Taylor Shelly (1935) and Bennett (1914), it has been understood that stress is resultant of many causes but here over expectation by the organization from employees and vice versa by the employee from the organization is major causes that needs be addressed at an appropriate level. Future researchers must also provide innovative solutions in upcoming studies.

\subsection{Stress Models}

Initially, the concept of stress was described as physical and psychological 
responses to newly exposed demands enforced on individuals. Later on, some expansions become part of stress like behavioral, perceptual, cognitive and psychological symptoms that are the result of complications experienced by individuals. The agreement related to stress terminologies is present but it's really difficult to develop a comprehensive theory of stress (Maslach1998, Cummings and Cooper 1998). Various researches have been conducted on stress and diverse stress models were developed during different eras. The stress models include:

- "Role Stressors Kahn et al (1964)"

"Stress is the outcome of stressors, which are, Role ambiguity, Role conflict, and Role overload". This shows that stress is totally relevant to the level/degree of stressors.

- Job Demand-Control Model (DCM) Karasek (1979)

When employees do not keep control over the job, and they don't have the ability to take a decision and manage results to meet high expectations of the organization is stress. This concept clarifies that balance between responsibility and celebrity must prevail.

\section{- Conservation of Resources (COR) Hobfoll (1989)}

When there is a gap between work done and organization's expectation, a situation occurs that is called stress. A Job resource associated with stress is working structure, organization's offering, interpersonal relationships and task structures. This concept shows a little bit different thing emphasizing the organizational structure interrelation between employee and nature of tasks assigned.

- Job characteristics Ganster and Schaubroeck (1991)

A strong relationship has been observed between human health (psychological and emotional responses) and stressors (job characteristics). This thing needs to be well understood that stressor effect the human health badly.

- Effort-Reward Imbalance (ERI) Siegrist (1996)

This theory is about employee's satisfaction level when employees are not satisfied with their rewards. As employees believe that they get less reward as compared to their work was done. Here it should be looked into that reward must be directly proportional to the nature of work and tasks that are relevant to satisfaction of employee. 


\section{- "Person-environment P-E fit theory (Edwards et al., 1998)"}

Dissatisfaction related to work environment leads to a stressor that results in stress. Three relationships have been found between stressor and stress. One is between "expectations and capacity", second "relationship of demand and supply of needs", third "mixture of expected capacity and supply of needs". These three relationships must be maintained at all cost, in order to avoid stress due to dissatisfaction.

- Cybernetic theory (Cummings and Cooper, 1998)

Here it is found that stressor and stress are in the sequential situation. Here it is clear that stress comes after the creation of stressors.

- Control theory (Spector, 1998)

Stress occurs when individuals have no grip over "workload", "schedule" and "complete freedom". This statement conforms to the idea that if management is poor in planning, then stress upon the employees is ultimate.

\subsection{Role Stressor Theory (Kahn et al, 1964)}

For this research work, Role stressor theory is referred. This theory was presented by Kahn et al, in 1964. "(Kahn et al, 1964)" defines stress as a result of role stressors. According to his role stressor theory, organizational aspects/factors create role expectations among role senders, and then this is transmitted to others as role pressures. Continuous pressure leads to signs of illness (Kahn et al, 1964). The organizational and job-related aspects in the form of demands and limitations that have been positioned on individuals that cause pressure on individuals is a Role stressor (Kahn, Wolfe, Quinn \& Snoek, 1964).

Role attributes have different effects on different individuals. Due to psychological benefits like status, ego and high self-esteem, people accept various roles (William \& Alliger, 1994). On the other hand, some potential cost also linked when individuals are unable to perform those roles. When proper guidelines regarding role's responsibility and authority are not provided to individuals, they perform less effectively and become dissatisfied that lead to stress (Lee \& Schular, 1980). Kahn et al define following three types of role stressors that include "Role conflict", "Role ambiguity" and "Role overload": 


\section{i. Role Conflict}

When incompatible and unreasonable expectations are imposed on employees, it is called role conflict. It's a situation when individuals have to perform two incompatible roles and due to that situation stress level rises (Kamel.I, 2011).

\section{ii. "Role Ambiguity"}

Role ambiguity occurs when individuals are not clear about their job, plans or tasks to be performed (Rizzo et al, 1970). A Certain amount of ambiguity leads to a creative environment and creative decision making. But clarification should be provided regarding goals and tasks so that individuals know about their starting point $\&$ evaluation criteria to avoid stress.

\section{iii. Role Overload}

When individuals are given more work in a limited time or task is assigned to individuals that are more than their ability, it results in role overload (Woosley, 2000). Challenging tasks within individual's capability usually increase employee's productivity and performance but when the demands of organization exceed, this leads to stress.

The author is in the opinion that role stressor theory carries a great wisdom because all these three stressors play a great role to create stress, among the employees. Although a number of theories have emerged so far but the importance of this theory brings a baseline that cannot be overemphasized. All the contemporary investigation and organizations have complete confidence in the validity of these stressors. Therefore all levels, whether it is employer or employee must understand the cause and effect of said stressors because not knowing a beautiful and successful concept sometimes may lead to disasters.

\subsection{Variables of Research}

Under mentioned variables have been considered for this research:

\section{Dependent variable}

Employee Performance is the dependent variable of this research.

\section{Independent variable}

Following are the independent variables of this research: 
Role conflict

Role ambiguity

Role overload

\subsection{Theoretical Framework}

Fig - 1 below indicates the framework:

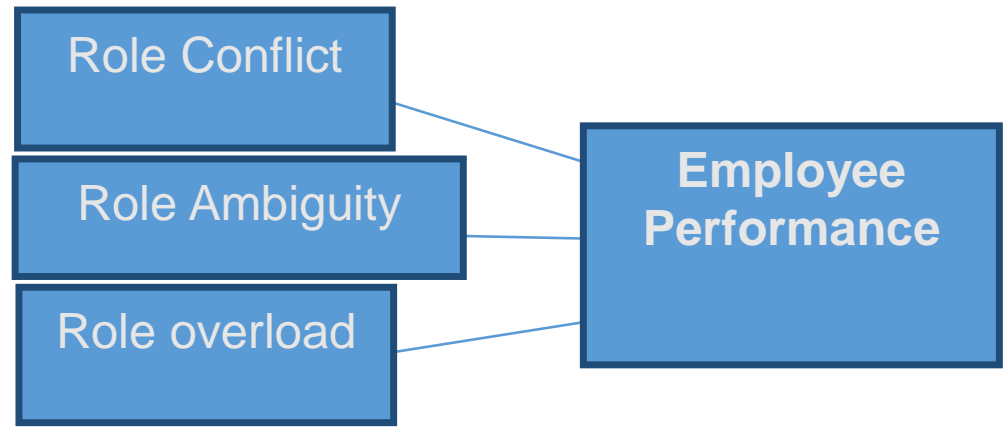

Fig - 1 gives the framework that clarifies that the factor of "role conflict", "role ambiguity" and "role overhead" seriously affect the employee performance. These all three factors/indicators put negative impact leading to loss of organization as well as of employees.

\subsection{Development of Hypotheses}

On the basis of above variables, following hypotheses are developed:

Hypothesis 1

Ho1: There is no impact of Role conflict on employee performance

Ha1: There is a significant impact of Role conflict on employee performance

Hypothesis 2

Ho2: There is no impact of "Role ambiguity on employee performance"

$\mathrm{Ha} 2$ : There is a significant impact of "Role ambiguity on employee performance"

Hypothesis 3

Ho3: There is no impact of Role Overload on employee performance

Ha3: There is a significant impact of Role Overload on employee performance

\section{RESEARCH METHODOLOGY}

In this research the cause and effect relationship between two variables i.e. 
dependent variable (employee performance) and independent variable "(role conflict, role ambiguity, and role overload)" is determined. So, the nature of research is explanatory in nature as one thought is linked with another and cause and effect relationship is developed between variables.

This research work is mainly based on quantitative type. The data is collected through a questionnaire for this research, which is converted to numerical form so that statistical calculations can be made for results. The sample size of this research is 150 employees, age between 25 years and above. The targeted population of this research work is middle-level employees of HBL bank.

The sampling technique used for this research work is non-probability convenience sampling as in this technique equal chances are not given to the participants. Non-probability sampling is less expensive, quick and convenient and usually used for questionnaire testing. Structured Questionnaire is used for data collection to meet the objective of this research. That Questionnaire covers all the aspects of role stressors that lead to stress. The questionnaire is divided into two parts i.e. Demographic (Personal profile) and "Role stressors (role conflict, role ambiguity, and role overload)".

Five points Likert scale is designed as a measurement tool for this research. Liker scale allowed all the respondents to share their views that how much they are agreed and disagreed with the statements. SPSS is used for ensuring the validity of the questionnaire. The structured questionnaire consists of 20 questions which comprehensively cover following important element that plays a role to cause stress:

I. Clarity of duties/responsibilities.

II. Experiencing stress at work.

III. Effect of stress on performance.

IV. Nature of stress results may be positive.

V. Type of physical disorder.

VI. The main cause of stress.

VII. Directionless performance.

VIII. Irrelevant tasks. 
IX. No proportion of responsibility \& authority.

X. Time constraint factor.

XI. Extra expectations.

XII. Shortage of help from parallel.

XIII. Cancellation of personal commitment due workload.

XIV. The imbalance between personal and profession life.

For this research work, both primary and secondary data are used. The primary data is collected through questionnaire and director interviews. However, the secondary data is collected case studies, articles, books and previous researchers which are used for the literature review. Further, SPSS software and Graph are used for data integration method. SPSS is used to analyze the required data and it integrates the data in tabular form and statistical models.

\section{Data Integration and Analysis}

Here a response of participants is being analyzed and interpreted. For this study, data is collected through survey questionnaire from 150 employees of HBL Bank. The data is analyzed through SPSS software.

\section{Questionnaire Analysis}

Under mentioned five in number tables and figures provide a complete analysis of the questionnaire designed for the purpose:

Table 1: Reliability Test

Case Processing Summary

\begin{tabular}{llll}
\hline & & No & $\%$ \\
\hline \multirow{3}{*}{ Cases } & Valid & 96 & 64.0 \\
\cline { 2 - 4 } & Excluded & 54 & 36.0 \\
\cline { 2 - 4 } & Total & 150 & 100.0
\end{tabular}

a. Listwise deletion based on all variables in the procedure.

Out of 150 employees, 96 are valid that equals $64 \%$

Reliability Statistics

\begin{tabular}{ccc}
\hline Cronbach's Alpha & Cronbach's Alpha Based on Standardized Items & No of Items \\
\hline .865 & .863 & 14 \\
\hline
\end{tabular}


Cronbach's Alpha coefficient is used as a quality indicator of the questionnaire for the Likert scale items, included in this study. The Cronbach's alpha value for the instrument used in this research is 0.865 , which indicates that this instrument is highly reliable as result shows a high level of internal consistency of the scale.

\section{Stress Affect Performance}

\begin{tabular}{llllll}
\hline & & Frequency & Percent & Valid Percent & Cumulative Percent \\
\hline \multirow{3}{*}{ Valid } & Yes & 125 & 83.3 & 83.3 & 83.3 \\
\cline { 2 - 6 } & No & 25 & 16.7 & 16.7 & 100.0 \\
\cline { 2 - 5 } & Total & 150 & 100.0 & 100.0 &
\end{tabular}

Table 2: Stress affects Performance

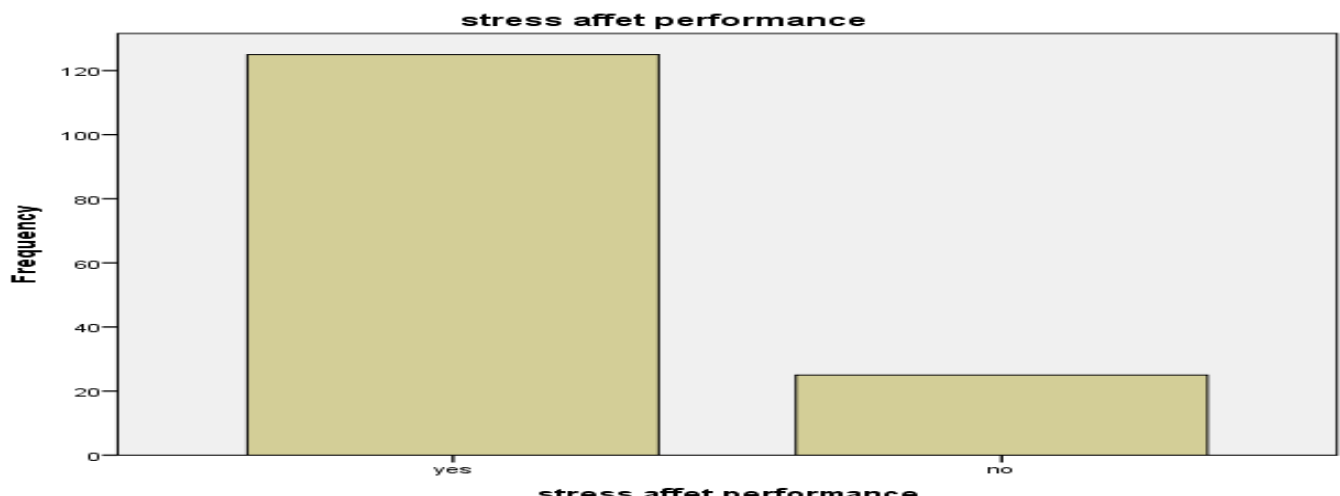

Figure 2: Stress effects Performance

The above table and graph show the responses of respondents about effects of stress on employee's performance. We ask through our questionnaire that stress affects performance or not. Out of 150 respondents, $83.3 \%$ believe that stress affects employee's performance level and only $16.7 \%$ believe that stress does not affect the performance of employees. Thus, the widely perceived concept that performance declines due to the stress level of the employees are very valid here.

\section{Positive Result of Stress}

\begin{tabular}{llllll}
\hline & & Frequency & Percent & Valid Percent & Cumulative Percent \\
\hline \multirow{3}{*}{ Valid } & Yes & 124 & 82.7 & 82.7 & 82.7 \\
\cline { 2 - 6 } & No & 26 & 17.3 & 17.3 & 17.3 \\
\cline { 2 - 6 } & Total & 150 & 100.0 & 100.0 & 100.0 \\
\hline
\end{tabular}


Table 3: Result of stress

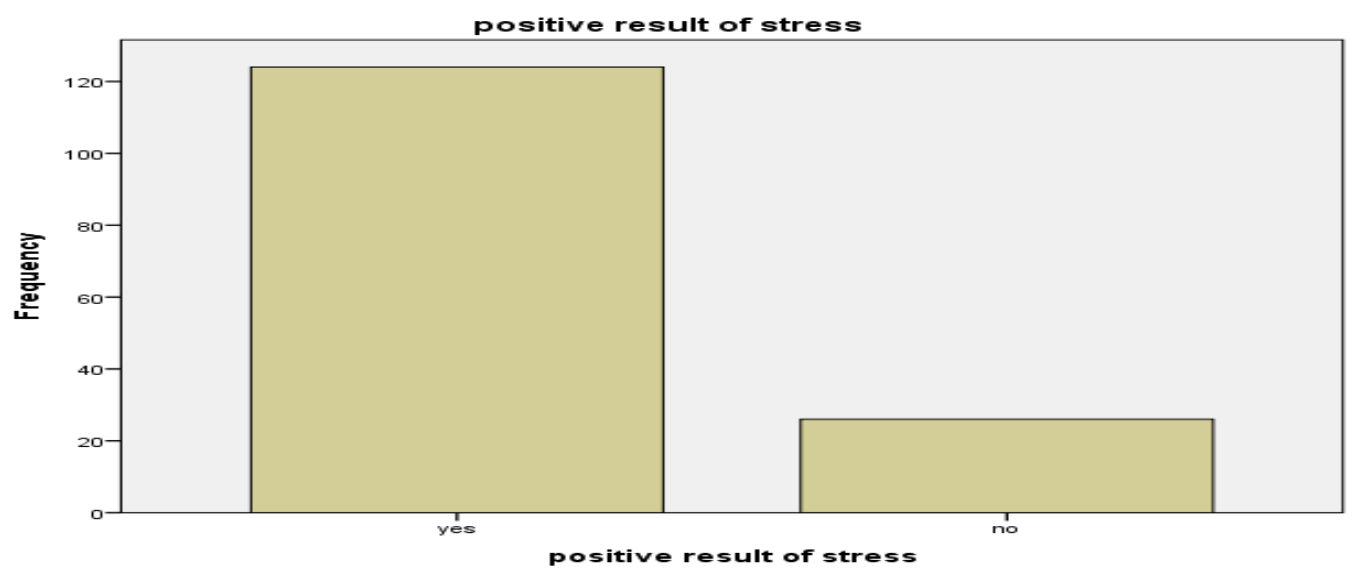

Figure 3: Result of stress

It is normally believed that stress always leads to the negative outcome but our findings show contrast results. Through our questionnaire, we ask employees of HBL regarding the positive outcome of stress. $82.7 \%$ respondents believe that stress is always not negative and it has a positive impact on performance level and only $17.3 \%$ believe that stress is always negative. In many of life activities, stress plays a positive role in reaching school by the student in time, reaching the office of employees in time. Studying hard to achieve a better score, working hard to earn more, lead to positive stress role.

\section{Type of Disorder}

\begin{tabular}{llllll}
\hline & & Frequency & Percent & Valid Percent & Cumulative Percent \\
\hline \multirow{4}{*}{ Valid } & Headache & 89 & 59.3 & 59.3 & 59.3 \\
\cline { 2 - 6 } & Anxiety & 13 & 8.7 & 8.7 & 8.7 \\
\cline { 2 - 6 } & Depression & 48 & 32.0 & 32.0 & 32.0 \\
\cline { 2 - 6 } & Total & 150 & 100.0 & 100.0 & 100.0
\end{tabular}

Table 4: Physical Disorder due to stress 
Figure4: Physical Disorder due to stress

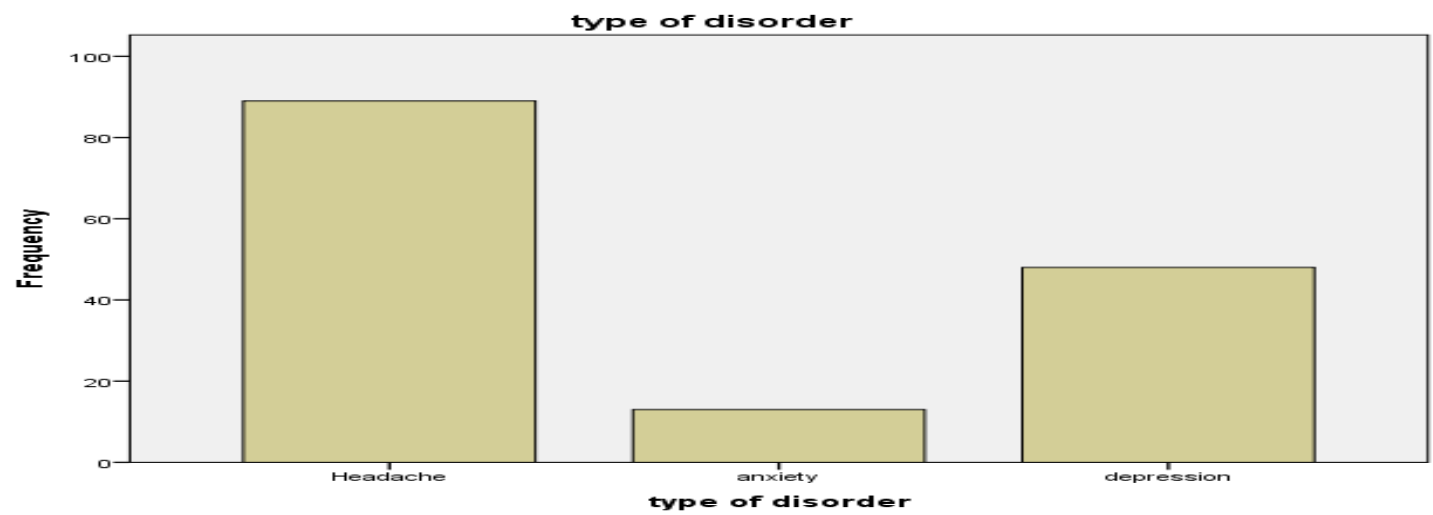

The findings of the result, collected through Questionnaire shows that due to stress, workforce faces some physical disorders like a headache, anxiety, depression etc. Almost 59.3\% employees suffer from a headache, $32 \%$ suffer from depression and $8.7 \%$ undergo anxiety during stress. Here it is very clear that stress is a huge cause of stress among the people that results into many diseases.

\section{Cause of Stress}

\begin{tabular}{llcccc}
\hline & & Frequency & Percent & Valid Percent & Cumulative Percent \\
\hline \multirow{4}{*}{ Valid } & Role Conflict & 25 & 16.7 & 16.7 & 16.7 \\
\cline { 2 - 6 } & Role Ambiguity & 11 & 7.3 & 7.3 & 7.3 \\
\cline { 2 - 6 } & Role Overload & 12 & 8.0 & 8.0 & 8.0 \\
\cline { 2 - 6 } & All of the above & 102 & 68.0 & 68.0 & 68.0 \\
\cline { 2 - 6 } & Total & 150 & 100.0 & 100.0 & 100.0 \\
\hline
\end{tabular}

Table 5: Cause of stress

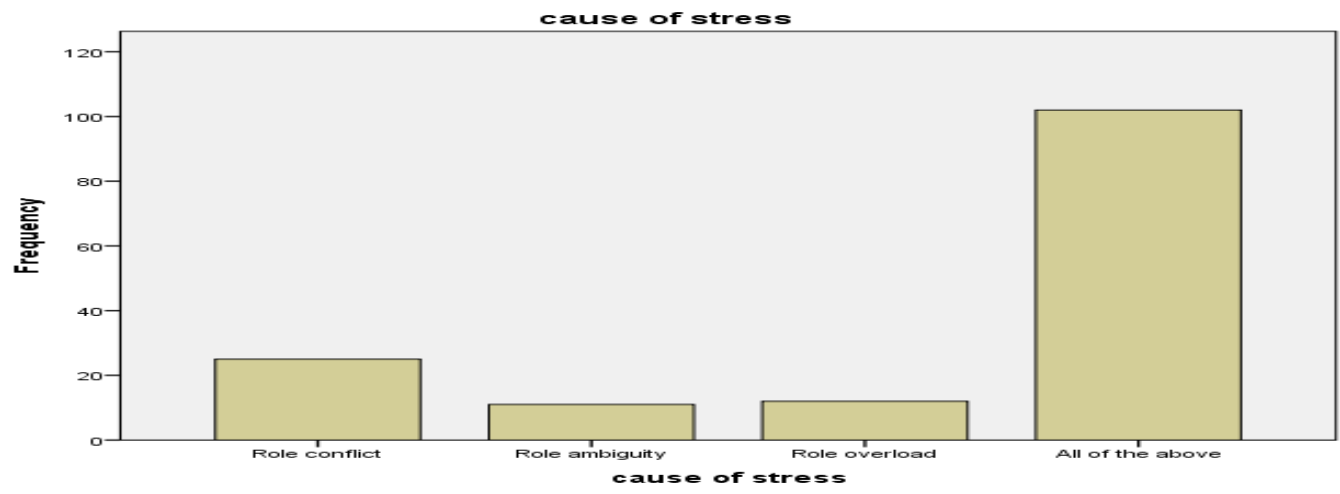

Figure 5: Cause of stress 
We ask respondents regarding the causes of stress through our questionnaire. The options given to respondents are "role conflict", "role ambiguity", "role overload" and all of the above. $68 \%$ respondents believe that all "role stressors i.e. role conflict, role ambiguity, role overload" are the cause of stress. $16.7 \%$ select role conflict as a cause of stress. Role ambiguity is the cause of stress according to $7.3 \%$ respondents and only $8 \%$ believe role overload is the cause of stress. Very high number of the population thinks that role stressors have a very high impact upon them resulting in a state of high stress.

\section{Correlation Analysis}

This analysis is based on all three hypotheses as follows:

Hypothesis 1

H 1: There is a "significant impact" of role conflict on employee performance Correlations

\begin{tabular}{llcc}
\hline & & Role Conflict & Performance \\
\hline \multirow{3}{*}{ Role Conflict } & Pearson Correlation & 1 & .321 \\
\cline { 2 - 4 } & Sig. (2-tailed) & 150 & .001 \\
\cline { 2 - 4 } & $\mathrm{N}$ & .321 & 96 \\
\hline \multirow{2}{*}{ Performance } & Pearson Correlation & .001 & 1 \\
\cline { 2 - 4 } & Sig. (2-tailed) & 96 & 96 \\
\cline { 2 - 4 } & $\mathrm{N}$ & & \\
\hline \multirow{2}{*}{ **. Correlation is } & significant at the 0.01 level (2-tailed). & \\
\hline
\end{tabular}

In the table above, the relationship between "role conflict and performance" was calculated through "Pearson correlation". The result shows that $r$ is close to 1 and it is .321 , and sig (2-tailed) is lesser than 0.05 , therefore, we accept the hypothesis and it proves that relationship exists between Role conflict and performance.

Hypothesis 2

H 2: There is a significant impact of "role ambiguity on employee performance" 


\section{Correlations}

\begin{tabular}{llll}
\hline & & Performance & Role ambiguity \\
\hline \multirow{3}{*}{ Performance } & \multicolumn{1}{l}{ Pearson Correlation } & 1 & .567 \\
\cline { 2 - 4 } & Sig. (2-tailed) & & .000 \\
\cline { 2 - 4 } & $\mathrm{N}$ & 96 & 96 \\
\hline \multirow{3}{*}{ Role ambiguity } & Pearson Correlation & .567 & 1 \\
\cline { 2 - 4 } & Sig. (2-tailed) & .000 & \\
\cline { 2 - 4 } & $\mathrm{N}$ & 96 & $150+$ \\
\hline
\end{tabular}

**. Correlation is significant at the 0.01 level (2-tailed).

Table 7: Relationship between Performance and Role ambiguity

In table 7 Relationship between Role ambiguity and performance was calculated through Pearson correlation. The result shows that $r$ is close to 1 and it is 0.567 , and sig (2-tailed) is lesser than 0.05 , therefore, we accept the hypothesis and it proves that relationship exists between Role ambiguity and performance.

Hypothesis 3

H 3: There is a significant impact of role overload on employee performance

\section{Correlations}

\begin{tabular}{|c|c|c|c|}
\hline & & Performance & Role overload \\
\hline \multirow{3}{*}{ Performance } & Pearson Correlation & 1 & .304 \\
\hline & Sig. (2-tailed) & & .003 \\
\hline & $\mathrm{N}$ & 96 & 96 \\
\hline \multirow{3}{*}{ Role overload } & Pearson Correlation & .304 & 1 \\
\hline & Sig. (2-tailed) & .003 & \\
\hline & $\mathrm{N}$ & 96 & 150 \\
\hline
\end{tabular}

In table 8, Relationship between Role overload and performance was calculated through Pearson correlation. The result shows that $r$ is close to 1 and it is 0.304 , and sig (2-tailed) is lesser than 0.05 , therefore, we accept the hypothesis and it proves that relationship exists between role overload and performance. In correlation analysis, all the hypothesis 
have been varied by tabular data. Very deliberately proved that all three stressors of 'role conflict', 'role ambiguity' and 'role overload' have resulted in a real amount of stress among the employees. So organizational management has to play a serious role so that stress level in organization level be kept at minimum level.

\section{CONCLUSION \& LIMITATIONS}

Our research and analysis show that stress is not always negative, sometimes stress is positive too. According to our findings, $83.3 \%$ respondents (150 employees of HBL Bank) of our research agree to the statement that stress affects employee's performance level that can be negative or positive. As 124 employees out of 150 agree with the statement that stress results are positive if stress level is manageable. Our findings show that stress is unavoidable and if it's not controlled initially, it leads to physical disorders like a headache, anxiety, and depression. The most common type of physical disorder is a headache, almost $59.3 \%$ employees suffer from a headache during stress. The second main type of physical disorder is depression, as $32 \%$ workforce face depression due to stress. Thus, Stress is emerging as an unavoidable factor for organizations. Our all three alternate hypotheses were accepted as the Pearson correlation test shows positive results through our findings. The results of Pearson correlation values are $0.321,0.576,0.304$ and sig. ( 2 tailed) value is less than 0.05 , so we accept all 3 hypotheses, as our result shows a positive relation between role stressors and employee performance. Hence, according to existing literature and our findings, stress declines the performance of employees and stress is the outcome of role stressors i.e. role conflict, role ambiguity and role overload.

\section{Future Work}

With the ever changing and dynamic environment, the role of stress on employees' performance needs to be studied in great depth. With the change in organizational structures and previously defined roles, new challenges are being faced by the workforce in the new technological era. Thus stress factors also need to be redefined in the new environment characteristics. 


\section{REFERENCES}

Selye H. 1936. A syndrome produced by diverse nocuous agents. Nature 138(3479, July 4):32.

Moorhead, H. and Griffin, F. (1998) Organizational Behavior. Houghton Mifflin Company, Boston. Lixivia

Kahn, R., Wolfe, D., Quinn, R., Snoek, J., and Rosentbal, R. Organizational stress: Studies in role conflict and ambiguity. New York: Wiley, 1964.

Coleman J.C. (1976) Abnormal Psychology and Modern Life (Indian reprint), Iniaporewalla, Bombay

Kahn, R. L., Wolfe, D. M., Quinn, R. P., Snoek, J. D., \& Rosenthal, R. A. (1964). Organizational stress:

Studies in role conflict and ambiguity. New York: Wiley

RobertL.Kahn Organizational Stress: Studies in Role Conflict and Ambiguity. John Wiley \& Sons Inc1964).

Arnold, H.J and Feldman, D.C (2000).Handbook of psychology, Industrial and Organizational psychology, p 304.

Robbins, S.P. (2004). Organization Behaviour. 11th Ed. New Jersey: Pearson Prentice Hall

Introduction to Visual Studio http://en.wikipedia.org/wiki/Microsoft_Visual_Studio

Introduction to Microsoft Access http://en.wikipedia.org/wiki/Microsoft_Access

"Learning Microsoft Access" - http://www.learnaccessnow.com

https://publicsector.wa.gov.au/workforce/development/human-resource-practitioners/ human-resourcescapability-framework

"C\# Tutorial Station" - www.csharp-station.com

Introduction to C \# - Anders Hejlsberg Distinguished Engineer Developer Division Microsoft Corporation

Learn C\# for beginner - www.comletecsharptutorial.com

HRM Standards 2012 